\title{
20 User-Centered Design Approaches for Web Mapping Applications: A Case Study with USGS Hydrological Data in the United States
}

\author{
Ming-Hsiang Tsou*, Judd M. Curran** \\ * Department of Geography, San Diego State University, CA, USA \\ ** Department of Geography, Grossmont College, CA, USA
}

\begin{abstract}
A User-Centered Design (UCD) approach can facilitate the development of effective user interfaces and generate comprehensive map contents for web mapping applications and services. To create a successful web mapping application, all major system components (GIS databases, web map servers, and web map browsers) should satisfy the needs of users and fulfill the objectives of mapping services. Different countries may have different user needs and mapping objectives. This research proposes a five-stage developmental framework (based on UCD approaches) for two major components of web mapping services: web map user interface (functions) and web map display layers (map contents). The five-stage framework (strategy, scope, structure, skeleton, and surface) of a UCD approach can provide comprehensive guidelines and implementation procedures for GIS developers and cartographers. This chapter uses a real-world web mapping example in the United States to illustrate the five stage UCD framework. The example prototype illustrates the display needs of U.S. Geological Survey (USGS) hydrologic data and the required GIS tasks for water resource managers. The web map prototype is evaluated by domain experts and users in USGS to analyze the effectiveness of a web mapping toolset and interface. This research suggests that full adoption of a UCD approach will improve the quality of web mapping and provide more useful geospatial information services for various users.
\end{abstract}

\subsection{Introduction}

Web-based mapping services utilize client/server computing technologies to combine different types of geospatial data and map layers from different sources into a single viewing environment (a map viewer or a map browser) via the Internet. It is essential to provide a user-friendly user interface to facilitate the access of geospatial information via map viewers or browsers. However, one major challenge 
of web-based mapping applications is that the users of web mapping services are much more diverse and unknown compared to traditional GIS users. Most web map users do not have any GIS training or cartography knowledge (Tsou, 2003). Therefore, the importance of providing a user-friendly and intuitive design of web mapping applications for various map users should not be underestimated.

In the United States, web-based mapping services have been adopted by many federal government agencies, including the U. S. Geological Survey (USGS), U.S. Census Bureau, National Aeronautics and Space Administration (NASA), and National Oceanic and Atmospheric Administration (NOAA). For example, the National Map (http://nationalmap.gov/) and the National Atlas (http://www.nationalatlas.gov/) developed by USGS provide thematic mapping services that allow educators and students to learn more about various aspects of the United States. NASA created the Earth Data Gateway (http://esg.cos.gmu.edu/web/guest/home ) to integrate various earth science data and satellite imagery with on-line viewing and browsing capabilities for scientists and researchers (Figure 20.1). NOAA established on-line real-time national weather services (http://www.nws.noaa.gov/) to show forecasted temperatures, air quality, fronts, precipitation, and extreme weather warnings (tornadoes, severe thunderstorms, flash floods and marine hazards).

The design of user-friendly interfaces is a key component to the success of these popular mapping services. Most web mapping services provided by U.S. govern-

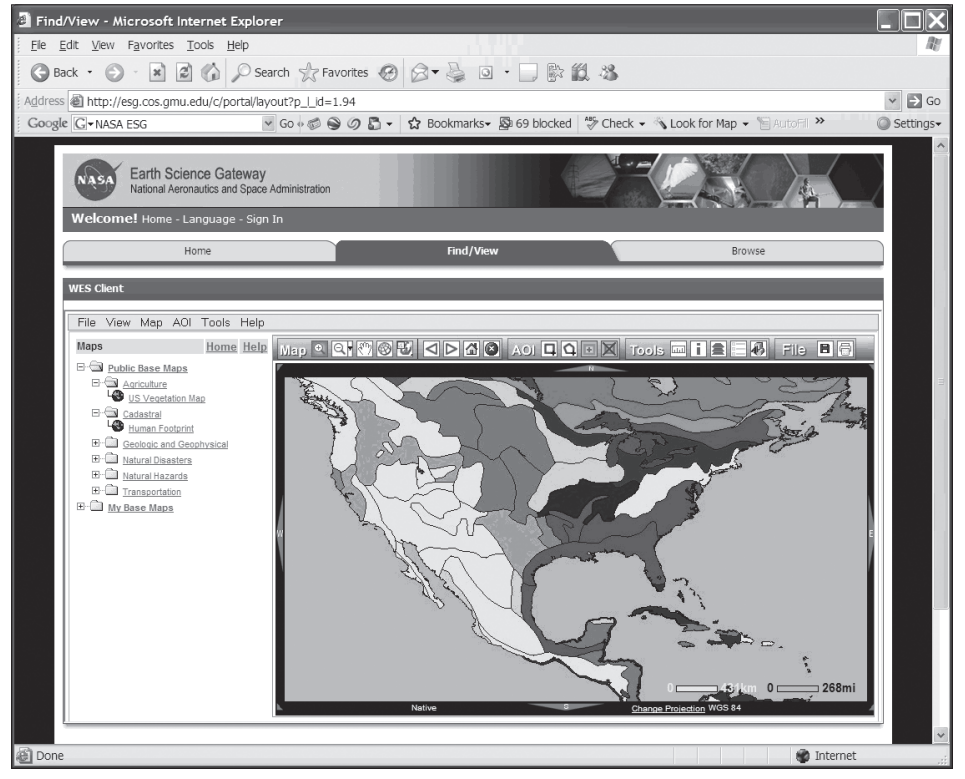

Fig. 20.1 The NASA Earth Science Gateway Map Viewer.

(URL: http://esg.cos.gmu.edu/c/portal/layout?p_1_id=1.94) (Access date: 1-29-2007). 
ment agencies are developed by a comprehensive procedure including user needs analysis and user-centered designed approaches. With the help of UCD approaches, publicly accessible mapping services can provide user-friendly interfaces and easyto-learn tools for both the general public and domain users.

The design of web mapping applications include three major tasks: user interface design, map content design, and the context of map usage (modified from Nivala at. al, 2005). In this chapter, the adoption of UCD methods to facilitate effective user interface design and comprehensive map contents is illustrated. The usability of web mapping applications will be improved by UCD approaches. The main tasks of UCD approaches for web mapping include the early involvement of map users, user needs analysis, map content design, web mapping function analysis, prototype testing and implementation, evaluation of prototype by users, and iterative revision procedures. This chapter will present the major components of UCD and implementation procedures for UCD applied to web-based mapping services. A real-world web mapping example (prototype) will be used to demonstrate the implementation of UCD approaches and the evaluation procedures for web mapping applications. The example is a web-based mapping tool for accessing, displaying, analyzing, and querying USGS hydrologic data for water resource management. The web map prototype is evaluated by domain experts and actual users and revised based on UCD approaches.

\subsection{The Role of the Map User}

From a cartography perspective, the map user has always played a very important role in the traditional cartographic communication paradigm (Figure 20.2a). A good map maker is required to understand how maps have been used by different map users with different needs including map purpose, usage time, and required content. The map user can also provide valuable feedback to the map maker for improving map design. However, the feedback and the revision of maps are usually not real-time.

The role of the map user in the development of maps becomes significantly more important in web-based mapping applications (Figure 20.2b). The map user can change map content immediately by manipulating a map browser (user interface). An example of this type of manipulation is zooming in and zooming out. The role of the map maker has been transformed into a collaboration of efforts between spatial databases, web map servers, and map browsers. Maps within a web-based mapping application are dynamic objects (pictures or data streams) that can be transferred and requested between web map servers and map browsers.

Therefore, to create a successful web mapping application, all major system components (Databases, Web map servers, and map browsers) need to adopt a UCD 
a. Traditional cartographic communication, modified from Robinson (1952).

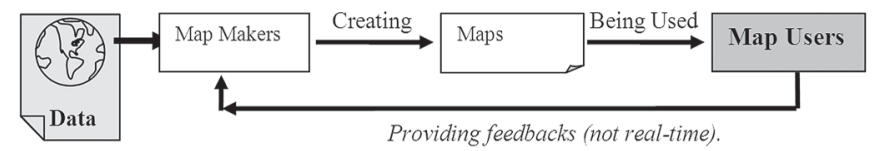

b. Interactive web-based mapping communication framework.

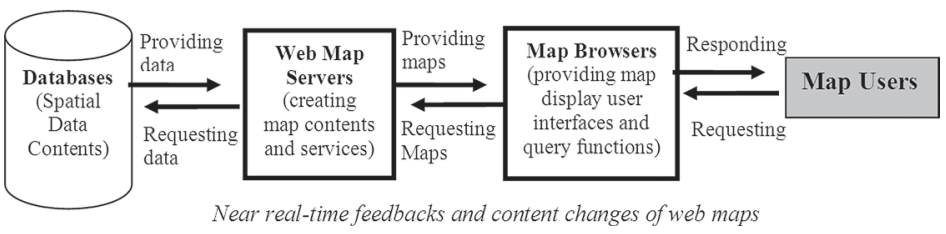

Fig. 20.2 The roles of users in traditional cartography and web-based mapping applications.

approach to ensure that maps generated by these systems are effective in meeting the needs of the map user.

User centered design is one of the major research areas in computer science and human computer interaction (HCI). Many GIS research projects have emphasized the importance of Human-Computer Interaction (HCI), user interfaces, and usercentered design approaches (Gould, 1989; Mark and Gould, 1991; Medyckyj-Scott and Hearnshaw, 1993 ; Nyerges et. al, 1995; Peterson, 1999). One major focus area of UCD approaches is design of the user interface. The user interface plays an important role in bridging communication between users and web mapping systems. Similar to the development of computer software, user interface design evolved from command line scripting, macro languages, menu-driven interfaces, and graphical user interfaces (GUIs), to direct manipulation interfaces (Tsou and Buttenfield, 1997; Shneiderman, 1998). The UCD approach can improve the design of user interfaces and provide user-friendly and effective tools for information access and manipulation.

The 1999 ISO Standard 13407, "Human Centered Design for Interactive Systems", outlines detailed UCD procedures and the importance of UCD methods. These procedures and methods focus on the interactive process of system development with user participation and evaluation. This standard illustrates five major steps for the implementation of UCD applications. The first step is the development of a plan with a user-centered focus. The second step is to understand and determine the context of use. The third step is to specify the user and organizational requirements. The fourth step is to produce design solutions. The fifth step is to evaluate the design using established requirements. One important aspect of the ISO 13407 
Standard is that each step is part of an iterative loop. For example, the results of the fifth step can be applied to the second step creating an iterative loop of user feedback and revision (ISO, 1999). The iterative process will continue until the objectives are satisfied. For web-based mapping applications, UCD can be used as a set of practical guidelines for design and software implementation processes.

\subsection{A Five-Stage User Centered Design Framework for Web-based Mapping Applications}

As illustrated in Figure 20.2b, there are three major components to the design of web-based mapping applications: databases, web map servers, and client-side map browsers. The following paragraphs will introduce a conceptual design framework for the three web mapping components adopted from UCD approaches. This example originated from the book, The Elements of User Experiences: User-centered Design for the Web, by Jesse James Garrett (Garrett, 2002).

In the book, Garrett describes five progressive levels of website design and implementation procedures. All website design and implementation should consider the following five stages:

- Stage 1: Strategy plane: What do we want to get out of the site? What do our users want?

- Stage 2: Scope plane: Transformation of strategy into requirements: What features will the site need to include?

- Stage 3: Structure plane: Giving shape to scope: How will the pieces of the site fit together and integrate?

- Stage 4: Skeleton plane: Making structure concrete: What components will enable people to use the site?

- Stage 5: Surface plane: Bringing everything together visually: What will the finished product look like?

(Garretts, 2002, URL: http://jjg.net/elements/, accessed on 11-18-2006)

Garrett's five-stage framework is similar to the ISO standard 13407, "Human Centered Design for Interactive Systems". However, Garrett's framework is more specific to the design of web applications rather than general software packages. It also emphasizes the two major components of websites: content design (information architecture) and user interface design. Moreover, the ISO 13407 standard places emphasis on the progressive nature of the framework. That is, each development stage must be completed sequentially. Garrett's work indicates that each development stage can be overlapping if necessary. For example, the development of the structure stage can start before the completion of the scope specification 


\begin{tabular}{|c|c|c|}
\hline & $\begin{array}{l}\text { Web Map User Interface Design } \\
\text { (functions) }\end{array}$ & $\begin{array}{l}\text { Web Map Display Layers } \\
\text { (data contents) }\end{array}$ \\
\hline Surface & $\begin{array}{l}\text { A1 Window arrangement and the } \\
\text { actual use of graphic icons, buttons, } \\
\text { windows, and hyperlink for the user } \\
\text { interface. } \\
\begin{array}{l}\text { @ Zoom In } \\
\text { Zoom Out }\end{array}\end{array}$ & 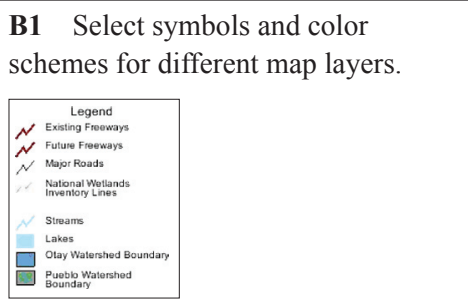 \\
\hline$\widehat{\bigoplus}$ & $\begin{array}{l}\text { A2 (Grouping functions) } \\
\text { - Map Display Window } \\
\circ \text { Zoom-in } \\
\circ \text { Zoom-out } \\
\circ \text { Pan } \\
\text { - Tool Box Window } \\
\circ \text { Query } \\
\circ \text { Identify } \\
\circ \text { Show attributes }\end{array}$ & $\begin{array}{l}\text { B2 (Arrangement of map layers) } \\
\text { - Base layers: } \\
\circ \text { Roads } \\
\circ \text { Highways } \\
\text { - Hydro-layers: } \\
\circ 2006 \text { monitoring sites } \\
\circ 2005 \text { monitoring sites }\end{array}$ \\
\hline Structure & $\begin{array}{l}\text { A3 (Formalized function list) } \\
\text { - Map Display functions } \\
\text { - Spatial identify functions } \\
\text { - Query functions } \\
\text { - Data download functions } \\
\text { - Help functions and on-line } \\
\text { tutorials }\end{array}$ & $\begin{array}{l}\text { B3 (Itemized data objects) } \\
\text { - Streams (shapefiles) } \\
\text { - Watershed boundaries (ArcSDE) } \\
\text { - Water gage sites (shapefiles) } \\
\text { - Roads (shapefiles) } \\
\text { - Metadata (text files) }\end{array}$ \\
\hline Scope & $\begin{array}{l}\text { A4 (Functional specification) } \\
\text { - Interactive map manipulation } \\
\text { (Zoom-in, Zoom-out, to interested } \\
\text { areas). } \\
\text { - Query water quality at monitoring } \\
\text { sites within specific watersheds. } \\
\text { - Download GIS data if needed. } \\
\text { - Help and online assistant tools. }\end{array}$ & $\begin{array}{l}\text { B4 (Map content requirement) } \\
\text { - Display hydrological maps. } \\
\text { - Identify real-time water gages } \\
\text { and create links to the gage data. } \\
\text { - Descriptions of these maps and } \\
\text { data. }\end{array}$ \\
\hline Strategy & \multicolumn{2}{|c|}{$\begin{array}{l}\text { C5 (Strategy plan) } \\
\text { - User Need Example: Hydrologists need to gather and query hydrological } \\
\text { data and information for the management of watersheds. Web-based } \\
\text { mapping is the best solution because web-based maps are more accessible } \\
\text { and easy to use compared to traditional GIS. Users do not need to install GIS } \\
\text { locally. } \\
\text { Map Service Objective Example: This mapping service can help } \\
\text { hydrologists manage watersheds more effectively. }\end{array}$} \\
\hline
\end{tabular}

Fig. 20.3 The five stages of user-centered design approaches for web mapping applications. 
stage. If there are major changes in the design structure, those changes can be reexamined immediately on the previous scope stage and appropriate modifications can be implemented. This research utilizes Garrett's five-stage approach for the design of web-based mapping applications with user interfaces, map contents, and map display characteristics. Figure 20.3 illustrates five different design levels that consider the dual aspects of web mapping: the user interface design and the map contents/display.

From a developer's perspective, there are two major design tasks of web mapping applications: functionality and map contents. This research proposes a design framework through five development stages (based on Garret's framework) for the major components of web mapping services: web map user interface (functions) and web map display layers (data contents) (Figure 20.3).

The initial stage of web map application design is the Strategy stage. This first stage should focus on the definition of user needs and the objectives of mapping services. Figure 20.2 uses a hypothetical situation to illustrate the beginning of the design processes for web mapping services. In this example, a federal agency creates a mapping service designed for hydrologists to easily access watershed information to facilitate decision making. The objective of mapping services in this example is to help hydrologists manage watersheds more effectively. The user need is defined as the need for accessible web-based information and tools for hydrologists.

The second stage, the Scope stage, focuses on the identification of the web mapping service scope. There are two aspects of the Scope stage: functional specification and map content requirements. The functional specification involves identification of the major tasks as determined by user needs and map objectives. In the example presented, the major tasks include interactive map manipulation, querying attributes from water quality monitoring sites, and downloading GIS data. The map content requirement includes the display of hydrological maps, access to real-time water monitoring sites, and integration of map hyperlinks to the realtime hydrologic data. The website also needs to provide ancillary information about these maps (metadata).

In the third stage, the Structure stage, design issues focus on the formalization of mapping functionality and the itemization of map data contents. For the user interface, this stage focuses on creating a comprehensive list of mapping functions such as map display, spatial query, buffering, data download, and help functions. Each function should be intuitive and unique to fulfill the functional requirements indicated in the Scope stage. In the design of data content, a focus on itemizing data objects and creating a complete data list based on stage two (content requirements) findings is emphasized. For example, to display hydrological maps, the list of data objects should include streams, water gage sites, roads, watershed boundaries, etc.

The fourth design stage is the Skeleton stage. In the Skeleton stage, the focus shifts to the arrangement of data objects into a meaningful category and the grouping of 
mapping functions with a conceptual hierarchy. For example, the [zoom-in], [zoomout] and [pan] functions should be grouped together in the map display window. In data content design, the data layers should fall into one of two different categories: hydrologic layers (the main theme) and base layers (supporting information).

The Surface stage is the final and most important stage. In this stage, the actual design of web map user interfaces and the incorporation of map contents is completed and used directly by map users. The design of graphic icons, buttons, and window layout are major functional tasks in this stage. For map contents, selecting symbols, text fonts, and color schemes for different map layers is completed in this stage.

The five stages of a UCD approach for web mapping applications (Figure 20.2) can provide a comprehensive set of guidelines and implementation procedures for web GIS developers and cartographers. This research suggests that UCD methods can improve the design of the web mapping user interface, enhance web mapping content (layers), and provide useful geographic information services for targeted users.

\subsection{The Implementation of Databases, Web Map Servers, and Map Browsers}

The five stages of UCD can be applied to the implementation of three major web mapping components: databases, web map servers, and the client-side map browsers. The implementation of each component is carried out in different stages using UCD methods. An evaluation method is used at the end of the process to determine if the final mapping service product satisfies user needs and mapping objectives. If some of the needs and objectives are not met, then the developer returns to previous stages of the process to revise the design of the web mapping application. The following describes the relationship between the three web mapping components and the five design stages (Figure 20.3):

- Databases. In a web mapping application, GIS databases are usually the first major task in the establishment of web mapping applications. GIS databases are connected with the web map server to provide geospatial information, to display maps, and to query attributes. Database design is carried out in the first two design stages under the web map display layers column (B3, B4) (Figure 20.4). The developer identifies the scope of data required in the applications (B4) and then creates a comprehensive list (B3). A GIS database is then created by collecting all data objects from the list and combining them into an integrated relational database or multiple data files. The GIS database will be used for the web map server and to transform data objects into multiple map layers in the final map viewers or browsers. 
- Web Map Server. In the Web Map Server component, the two stages (A3, A4) under the function column (scope and structure) provide suggestions for the selection and setting of the web map servers. System developers can gather information collected in the functional specification (A4) and the list of formalized mapping functions (A3) for the design and implementation of web map servers. Different web map servers (such as ESRI's ArcIMS, AutoDesk's MapGuide, and open source MapServer) provide different types of mapping functions and GIS capabilities (Tsou, 2004). Application developers choose appropriate web mapping engines (software packages) that provide enough functions to fulfill the needs from A3 and A4. Considerations include both the characteristics of mapping formats (such as image-based engines or stream-vector-data based engines) and customizable functions (identification, buffering, changing symbols and colors, etc.). The selected web map server is then connected with the GIS databases and provides mapping functions based on requests from map browsers and map users.

- Map Browsers. Map browsers are usually the most visible component in the development of web mapping applications. The design of map browsers cover dual aspects of UCD methods. This includes both the design of web map user interfaces and the symbolization of web map display layers. In designing map browsers, the tasks cover all aspects of the Skeleton stage and Surfaces stage (A1, A2, B1, B2) (Figure 20.3). Displaying map layers in map browsers utilizes

\begin{tabular}{|c|c|c|}
\hline & $\begin{array}{l}\text { Web Map User Interface } \\
\text { Design (functions) }\end{array}$ & $\begin{array}{l}\text { Web Map Display Contents } \\
\text { (data layers) }\end{array}$ \\
\hline & EVALUATION & EVALUATION \\
\hline Surface & $\begin{array}{l}\text { A1: Window arrangement } \\
\text { and the actual } \\
\text { implementation. } \\
\text { Map Browser }\end{array}$ & $\begin{array}{l}\text { B1: Select symbols and } \\
\text { color schemes for different } \\
\text { map layers. } \\
\text { Map Browser }\end{array}$ \\
\hline$\widehat{\text { Skeleton }}$ & $\begin{array}{l}\text { A2 (Grouping functions) } \\
\text { Map Browser }\end{array}$ & $\begin{array}{l}\text { B2: (Arrangement of map } \\
\text { layers): } \\
\text { Map Browser }\end{array}$ \\
\hline $\begin{array}{c}\text { Structure } \\
\text { St }\end{array}$ & $\begin{array}{l}\text { A3 (Formalized function } \\
\text { list) } \\
\text { Web Map Server }\end{array}$ & B3 (Itemized data objects) \\
\hline Scope & $\begin{array}{l}\text { A4 (Functional } \\
\text { specification) } \\
\text { Web Map Server }\end{array}$ & $\begin{array}{l}\text { B4 (Map content } \\
\text { requirement) } \\
\text { Databases }\end{array}$ \\
\hline$\widehat{\text { Strategy }}$ & $\begin{array}{l}\text { C5 (Strategy plan) } \\
\text { - User Need } \\
\text { - Map Service Objective }\end{array}$ & \\
\hline
\end{tabular}

Fig. 20.4 The implementation of user-centered design approaches for web mapping components (map servers, databases, and map browsers) with iterative feedback procedures. 
the GIS databases provided by the web map servers. The GIS functions and user interfaces will be supported by the web map servers. The design of map browsers are the most critical component of web mapping services because they are used directly by map users. A poorly-designed map browser prevents users from accessing information and results in the failure of the mapping service.

One new procedure added in Figure 20.4 is the evaluation process. This process is implemented after the completion of web map user interfaces and map display layers. The evaluation process gathers user feedback through various methods including user testing, questionnaires, focus group discussions, and individual interview methods. The results of the evaluation process for both map contents and mapping functions is examined to see if the final mapping product satisfies the goal of user needs and mapping objectives. Evaluation results are used to revise various stages of development and are an iterative process in UCD methods. For example, evaluation findings may suggest that a new mapping function, such as buffering, is needed for some users. Developers will then modify the Scope stage (A4) to incorporate the new buffering function. This change will also be carried out in A3 (Structure), A2 (Skeleton), and A1 (Surface) design procedures. If user feedback indicates that a graphic icon in the user interface design is misleading, the revision procedures will only be carried out at the Surface stage (A1). The cost of revising A1 level design issues is much less expensive than the cost of revision within a series of levels beyond A1.

The next section will illustrate an actual implementation example of web mapping applications with UCD methods. The example involves the development of webbased geospatial information services created within the U. S. Geological Survey (USGS) for management of real-time surface water hydrology.

\subsection{Case Study: Web-based Geospatial Information Services for the Management of Real-time Surface Water Hydrology}

The five stages of user-centered design methods illustrated in the previous section (Figure 20.4) can be adopted in various web mapping applications. This section discusses a real-world case study in the United States to illustrate actual design procedures and the adoption of UCD methods. This case study involves the development of a web-based mapping service designed for management of real-time surface water hydrology (Curran, 2005) within the California Water Science Center of the USGS. According to the framework of UCD methods (Figure 20.4), design processes can be carried out in various steps (C5, A1-A4, B1-B4, and the evaluation step). 


\subsubsection{The Strategy Stage (C5: Strategy plan)}

At the beginning of the design stage, two items need to be specified: user needs and map service objects. In this case study, the user needs and mapping objectives are gathered by interviewing several water resource professionals within the USGS to create a statement of general user needs for this new mapping service (Curran, 2005).

User Needs: Water resource managers trying to decide whether flooding is eminent in a particular urban area will need topographical data, land use data, and real time information on current stream flow and weather. The efficiency of the manager's decision making is influenced by the time expended to locate and download data on the Internet, convert data to a useable format, and analyze data using a GIS software utility. The multitude of Internet resources in different formats and locations impedes the efficiency of the decision making process.

Mapping Objective: The goal of this mapping service is to provide web-based mapping tools for enhancing the accessibility and usability of real-time hydrologic data.

\subsubsection{The Design of Spatial Databases (B4 and B3).}

The next step is to design spatial databases for the entire application. The procedure includes map content requirements (B4) and the itemization of data objects (B3).

B4 (Map content requirements): The data used in this new mapping service prototype are comprised of two main components. The first and most significant component is dynamic real-time surface water data. The other main component includes various static base coverages that, when combined with the real-time surface water data, create a more functional prototype for many hydrologic applications serving a diverse range of user expertise.

B3 (Itemized data objects): The data objects needed in this prototype follow the B4 specification and include two main components: real-time surface water data and base map layers. This step also identifies the type of databases or GIS data formats that are used in the project. The real-time surface water data is available from USGS in ESRI's Shapefile format (one data object). As a result, this project adopts Shapefiles as the GIS database format. The Shapefile map objects include the locations of all real-time USGS stream flow stations in California and attribute information including station number, station name, name of office in charge of operating the station, the frequency of field data collection, and the URL address for each station that references the station homepage in USGS websites. The other map component is the base map which is comprised of thirteen different Shapefiles as identified below: 
1. Rivers and streams

2. Major hydrologic units

3. Precipitation

4. Lakes

5. Major roads

6. Major highways

7. City boundaries

8. County boundaries

9. California state boundaries

10. Mexico boundaries

\subsubsection{The Design of Web Map Servers}

The design and implementation of web map servers for this application focuses on the general need for GIS functions (A4) and the actual GIS tools (A3) provided by the selected web map servers.

A4 (General GIS function needs and specification): Based on the user needs and map service objectives, the GIS functions include the following items:

1. The system can create and display dynamic multi-layered maps.

2. Maps can be resized and re-centered dynamically.

3. The system can perform spatial query of hydrologic data with attributes.

4. The real-time stream flow gage sites can be dynamically linked to related web pages.

5. Assistant tools for learning this web map application are incorporated into the design.

A3 (GIS Tools and formalized function list): Basic GIS tools are formalized for the web-based prototype using the A4 specification. The web-based GIS tools include:

1. A modifiable table of contents associated with multiple map layers.

2. A set of zoom and pan tools.

3. A set of query tools including identify, measure, search, and buffer functions.

4. A hyperlink function for water gage sites.

5. An online tutorial to guide users through the capabilities of the prototype.

These GIS toolkits can provide the user with a means for improved spatial understanding of hydrologic processes. At this stage, developers select the appropriate Web map servers for the project such as ArcIMS by ESRI, AutoDesk MapGuide, Integraph GeoMedia Web Map, or MapServer by Opensource. After a few evaluation procedures, ArcIMS by ESRI was adopted as the Web Map Server for this project. 


\subsubsection{The Design of Map Browsers}

The next step is to design map browsers and the display of map layers for this application. The procedures include A2 (function grouping), A1 (the layout of map user interface), B2 (arrangement of map layers), and B1 (symbol selection and color schemes). There are two types of map browsers available in version 4 of ArcIMS. One of the browsers operates via a Java applet and allows for increased client functionality, more customization, and more flexible display and analytical functions. The other viewer is HTML based. The Java viewer demands more intensive client-side processing than the HTML viewer and requires the installation of a Java plug-in. These requirements could create difficulty for some users and provide limitations to a broad user base. Consequently, the Java viewer is not used for the development of this prototype. The HTML viewer is selected because it allows some customization, utilizes JavaScript technology without the need for a plugin, and operates with thinner client-side processing demands. The following is a description of the A2, A1, B2, and B1 tasks.

A2 (Grouping functions): GIS tools are integrated into the website using ArcIMS Designer and include all of the interactive functions that are available for examining, querying, and analyzing the data. The tools used in this prototype can be grouped into four categories. For data presentation, the Legend, Overview, Zoom In, Zoom Out, Initial, Active, and Previous tools are provided. For navigation, the Pan, Move N, Move S, Move E, and Move W tools are provided. For information about the data, the Real-time, Identify, Query, and Find tools are included. For analysis, the Measure, Set Units, Buffer, Select, and Clear tools are integrated into the system. In addition, a Print tool is available. This suite of tools provides the user with a means for interactively exploring the data with the intent of improving spatial understanding of hydrologic processes and conditions.

A1 (The actual layout of map user interfaces): The design of a map user interface finalizes the layout and organization of the components of the system. Figure 20.5 illustrates the actual design and arrangement of map browser user interfaces including the map display box, map layer control and table of contents window, title, and GIS tool set. Developers select appropriate graphic icons and color scheme to design the actual buttons and menus for the map browser.

B2 (Arrangement of map layers): Using ArcIMS Author, the layer names, scale that each layer is displayed, the attribute used to label the features, the font, text size and color of the labels, the color, size, and style of symbols used to draw features, map and scale units, and initial extent are specified for each of the thirteen data layers. The initial extent is set to display the California boundary, Mexico boundary, surrounding area, and major hydrologic unit data layers with a user option to also display the counties and precipitation data layers (Figure 20.6). The other layers of the map will only display at larger scales requiring the user to zoom in before 


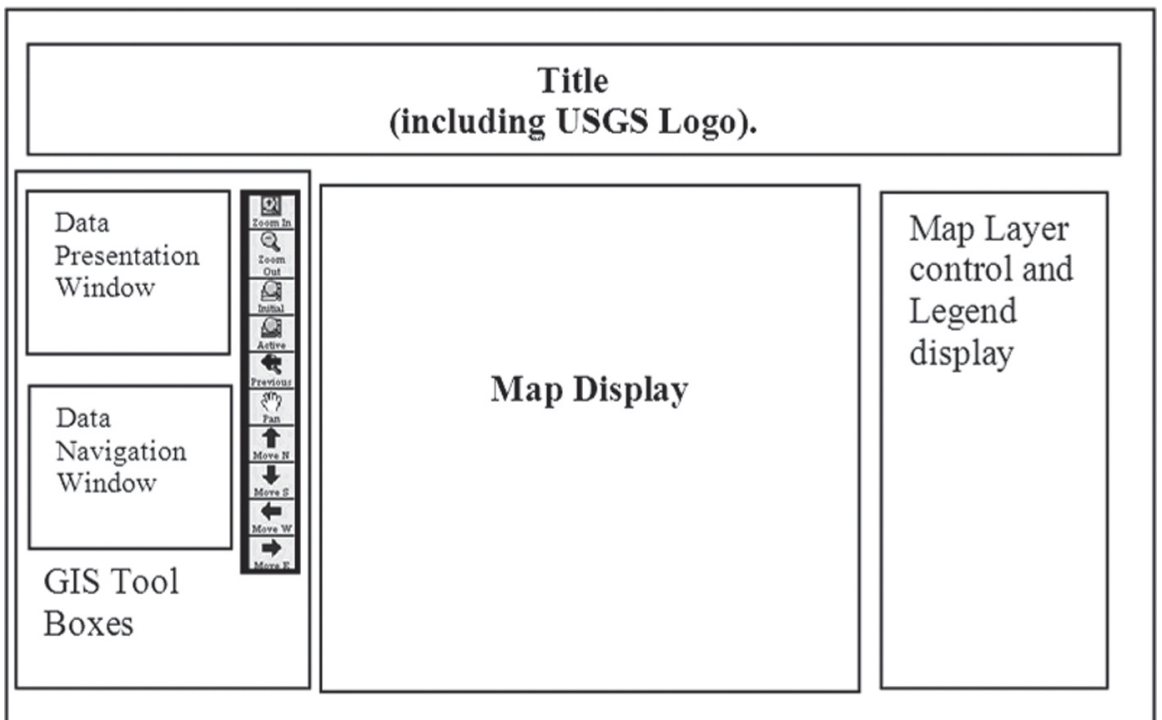

Fig. 20.5 The actual layout of map user interfaces.

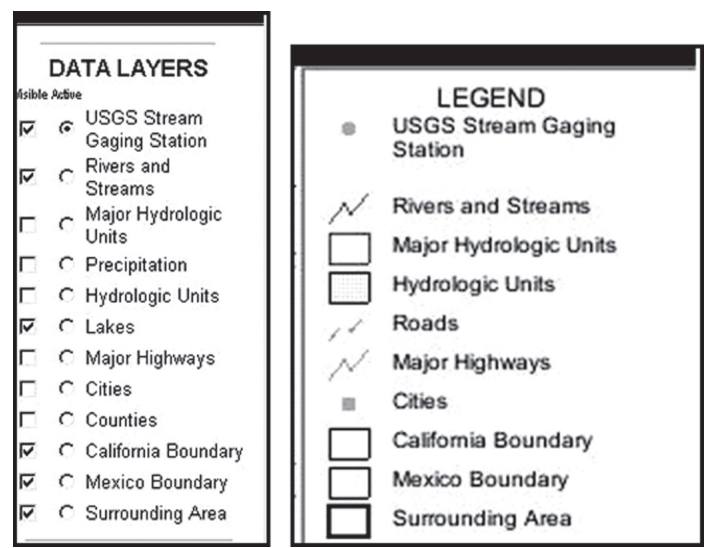

Fig. 20.6 The final design of map content layers, symbols, and color schemes.

those layers are added to the map. Displaying all of the data layers at the initial extent overburdens the map interface with features that could not be differentiated. Therefore, the map was designed to display additional data layers at certain scales to minimize cluttering and provide appropriate levels of detail.

B1 (Symbol Selection and Color Schemes): The symbology is uniquely colored for each of the features displayed along with the corresponding feature text to easily differentiate between features. An exception to this rule is the lakes coverage. With blue-filled polygons representing lakes, this coverage could not support blue 


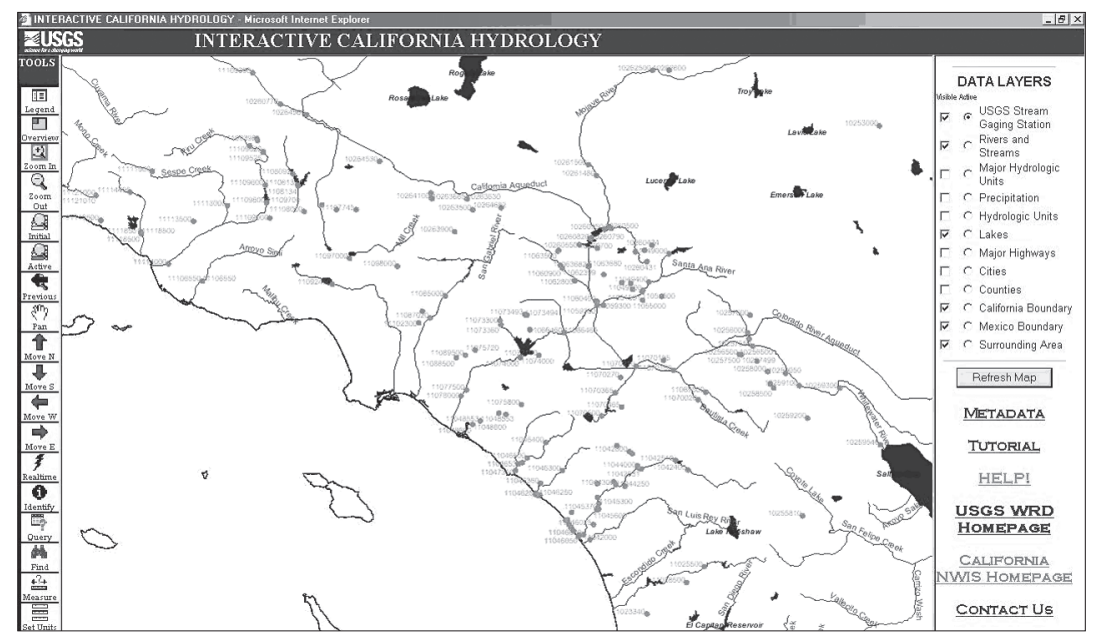

Fig. 20.7 The final product of map browsers in the user case (the customized ArcIMS HTML viewer).

label text because the text merged with the blue fill of the polygon background. Consequently, the lakes text labels were changed to black to stand out over the blue lake background. Because the cities and stream gaging station layers are both point coverages, square symbology is used to represent cities and circle symbology is used for stream gages to further segregate these features.

By combining A1, A2, B1, and B2 together, the well-designed map browser is able to display appropriate map contents and map layers for end users (Figure 20.7). Additional tools and links, such as Help, Tutorial, and Contact Us, were added into the map browser interface. Figure 20.7 illustrates the final product of the Map Browser, which will be used directly by water resource managers.

\subsubsection{Evaluation of the Context of Web Map Use.}

After the completion of web browser design and map layer arrangement, the next step is an evaluation of the effectiveness of web mapping tools in the context of map use. The user testing and evaluation of a prototype is an excellent way to determine the usefulness and functionality of a new system or application (Shneiderman, 1998). The evaluation methods focus on usability and functional aspects of the prototype for identification of future revision needs.

Usability problems are design flaws that a user may encounter while working with web mapping tools related to user control, flexibility, efficiency, legibility, understandability, feedback, error prevention, visibility, ease of use, consistency, standards, and accessibility (Nielsen, 1993). These design flaws can distract users 
from the overall purpose and potential of the prototype. Therefore, a comprehensive evaluation procedure is needed to identify potential usability problems in the tools and web browsers.

The target users of this prototype are employees within the USGS California Water Science Center. They work with water resource data and management of water resources on a daily basis. Because the prototype runs on an internal server within the USGS network, individuals other than employees of the USGS do not have access to the prototype. Consequently, the need for participants could only be met by employees of the USGS California Water Science Center. Fifteen professionals were solicited via email with the details of the research, review process, and participation instructions. Participation was presented as voluntary. Of the fifteen participants, eight responded with consent to participate.

The eight participants represented a wide range of expertise within water resources and included four Hydrologic Technicians, an Information Technology Specialist, a Hydrographer, a Hydrologic Data Assistant, and a Hydrologist. These participants are well-educated in the field of water resources and represent a broad spectrum of expertise in web-based GIServices. This group is suitable for the evaluation process because each individual can approach the prototype and tutorial-related tasks with unique perspectives insuring that most of the major usability problems are identified. In many system evaluation procedures, a small number of expert reviewers (four to five) can often provide adequate feedback to assess usability design (Nielsen, 1994).

To start the evaluation, participants simply click on the hyperlink sent in an email and a new browser window opens with the introduction webpage. This webpage, created in Microsoft FrontPage, contains a brief overview of the steps involved in the evaluation procedure, instructions on how to maximize their computer screen resolution, and the link to initiate the prototype and corresponding tutorial. The participants are then guided by the tutorial through the tools, data, and functionality of the prototype. During the evaluation procedure, participants can access a variety of help options including email links and telephone communication for technical support as well as a Help hyperlink to ESRI's ArcIMS Online User Support Center. Once the tutorial is completed, participants are directed to an online questionnaire via a hyperlink at the end of the tutorial. The questionnaire provides a medium for participants to give feedback on their evaluation of the prototype.

The sixty questions in the questionnaire are divided into five sections. In the first four sections, participants rate Prototype Interface Characteristics, Prototype Tools, Data Layers and Map Display, and the Prototype Tutorial using a scale of five options including Strongly Agree, Agree, Neither Agree Nor Disagree, Disagree, and Strongly Disagree (Figure 20.8). The fifth section of the questionnaire is composed of ten short-answer questions. These questions thoroughly address all aspects of the prototype including overall impression of the design, information 


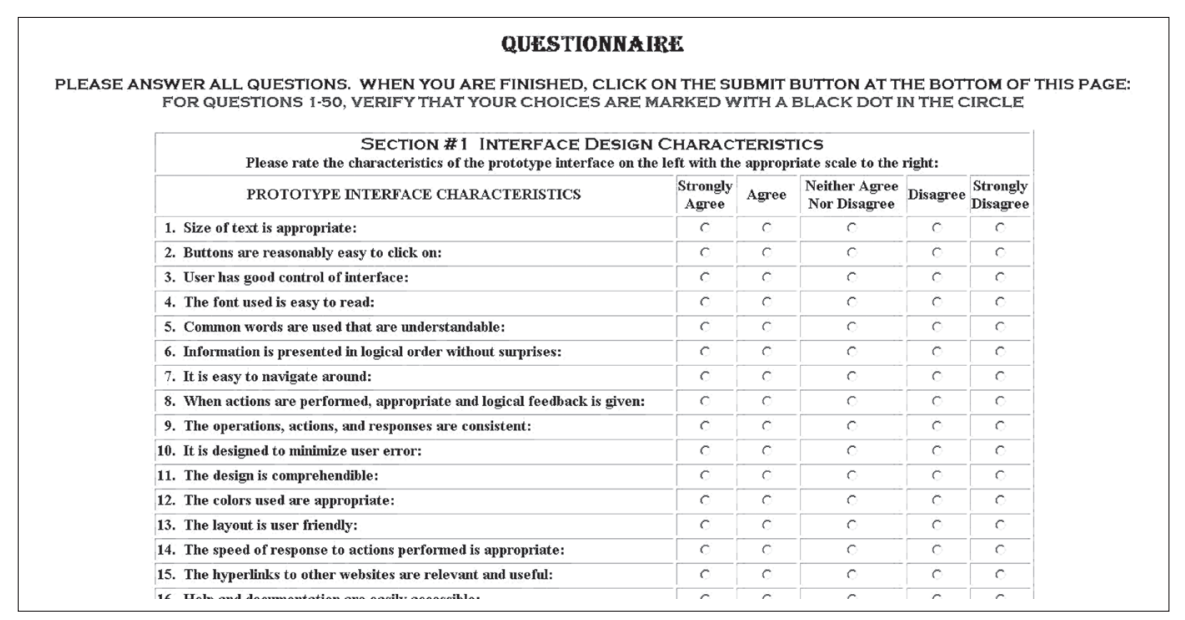

Fig. 20.8 Online questionnaire for heuristic evaluation.

content, performance, prototype tools, data, analysis capabilities, interface, realtime data access, usefulness, attribute data, comparison with the existing USGS water data webpage, and the Internet as a means of interaction with geospatial information. Participants type responses to the questions in a form text box. At the end of the questionnaire, participants enter their job title and date, and then click on the submit button to complete the evaluation. Responses are automatically transmitted via the Internet to the principle investigator when the submit button is clicked in tab-delimited text format. Each response is tagged with the question number for reference. The questionnaire was built with HTML and JavaScript in Microsoft FrontPage.

Results from the evaluation questionnaires in email format are transferred to a Microsoft Excel spreadsheet and categorized by each question. Excel is used because it allows for an organized way to manage and analyze the data efficiently. Next to each question or design characteristic, all eight responses are displayed and a summary of those responses is easily performed.

\subsubsection{Prototype Revisions}

Feedback from the evaluation questionnaires can be used to revise the prototype to eliminate usability problems. There are two major categories of prototype revision: map layer design revision and the functional revision. The map layer design revision is implemented by modifying the AXL file in ArcIMS Author and through script editing in the associated HTML and JavaScript files. For example, the color of feature label text was adjusted to match the features to improve legibility. The 
color of the roads features was changed to pink to create a greater dissimilarity from other line features. In addition, the background color of the major hydrologic unit layer was lightened and the outline color changed to light brown. These revisions improved the usability and legibility of the map interface.

The functional revisions are implemented based on feedback from the shortanswer questions in section five of the questionnaire. Problems with browser compatibility, especially the Firefox browser by Mozilla, could not be addressed within the scope of this project. It has been noted in recent publications that many websites are reporting functionality problems from users browsing with Firefox. The specific causes of these functionality problems, including failed pop-up windows that were experienced by one user, are not known. One reviewer suggested that query and find text entries should be case insensitive. This being an obvious design flaw, the appropriate JavaScript code was modified to support both upper and lower case searches and queries. The size of tool button images was increased from size sixteen to size twenty, and the font of the tool labels changed to Rockwell through HTML code modifications. These changes improved the legibility and ease of tool use. One reviewer suggested that the change between zoom clicks was too coarse when zooming out. Within the JavaScript code, the zoom factor was changed from a value of two to one and a half to reduce the change in scale for each zoom request. Another reviewer suggested that the font size of feature labels be increased. After increasing the font size, the map interface was visually overburdened with text. As an alternative to increasing the font size, each feature label was assigned a unique color to match the features. This change improved legibility without overcrowding the map interface.

In summary, the UCD approach provides a very effective, useful, and structured set of guidelines for the development and evaluation of this web mapping prototype. One important concept in the UCD approach is the iterative process of prototype development, evaluation, and revision. This case study is a good example of the benefits of a five-stage framework (Strategy, Scope, Structure, Skeleton, and Surface) for web mapping services and evaluation processes. The user-centered design approach can provide a comprehensive design framework and implementation procedure for GIS developers and cartographers.

\subsection{Conclusion and Discussion}

This paper suggested a five-stage framework based on UCD approaches for the development of web mapping applications. Along with significantly reduced cost of web server hardware and software packages, thousands of web map servers and services have been established recently. However, many web mapping services are poorly designed and many web mapping applications are not able to satisfy the 
needs of their targeted users. The UCD approaches provide very useful guidelines and instructions for GIS professionals and system developers who are focusing on web mapping applications. The five stage UCD framework provides comprehensive and detailed procedures for system developers to adopt step-by-step design tasks for the development of web mapping applications. The adoption of UCD approaches offers greater potential for improved quality of web mapping tools and provides more useful map information services for targeted users. However, from a software developer's perspective, there are still three major challenges related to UCD approaches. These challenges will need to be addressed in the future for improved usability of web mapping applications.

The first challenge is the accommodation of new web technologies. Web technologies are continuously changing at a rapid pace (Peng and Tsou, 2003). New web technologies will have significant impacts for the future development of web mapping applications. However, adopting new technologies in the development of web mapping applications will usually result in the need for another loop of UCD approaches to be carried out. Developers need to ensure that new web technologies can fulfill the needs of users and mapping objectives. In some cases, new web technologies could cause more problems in system usability if not properly evaluated. The additional iterative design processes for new web technologies may generate a significant delay in system implementation and the release date of new web mapping services.

The second challenge is in the diversity of users. Many UCD research projects indicate that different users have different needs of information services and thus may require different types of user interfaces. Map users from different countries with different cultural backgrounds may have different needs which could impact their learning of web mapping tools. For example, users from Asian countries might prefer different color schemes for displaying roads and highways compared to users from European countries. If a web mapping application provides two or three customized user interfaces for different user groups, it may potentially create inconsistencies and confusion for general users in the context of map use. Sometimes, a single version of user interface or map browsers can satisfy various user needs. For example, Google Earth, a web-based mapping application, is widely used by both scientists and K-12 students without multiple customized user interfaces. The perplexity of deciding whether to create multiple customized user interfaces for various users or to provide one single user interface for all different users requires consideration of the many factors involved in developing a system that meets the needs of the majority of users.

The third challenge is to inspire innovative user interface design for web mapping applications. UCD approaches emphasize the importance of user feedback and participation that will provide the quality check for the final version of system functions and user interfaces. However, UCD approaches can not facilitate 
innovative design concepts because these approaches are formalized in a progressive framework rather than a revolutionary method. Creating innovative user interfaces for web mapping is very important for the next generation of web mapping applications. Voice commands, 3D visual interfaces, and video-camera captures are some potential approaches. One good example of an innovative user interface is the recent release of the Nintendo video game console, Wii. This new video game system utilizes remote controllers with blue-tooth, infrared, and motion sensor technologies to create an immersive environment for video gaming. For the future development of web mapping applications, users may use similar controllers to open a map, zoom-in to a specific area, and identify spatial objects interactively on the screen with the use of remote controllers. Innovative user interface design can potentially provide a quantum leap in the usability of web mapping services. However, some innovative concepts may have a high level of risk because web technologies can potentially lack maturity and the required level of system performance may create limitations.

In summary, this chapter illustrates the UCD approach for the design and implementation of web mapping applications. These procedures and steps are very useful to help developers formalize the concepts of web services and get feedback from users. Research in the field of web mapping applications is still very young. Cartographers and Web Mapping Service developers will benefit from the exploration of more approaches to improved usability of web maps and to provide more effective maps via innovative web browsers and map viewers.

\section{Acknowledgements}

The authors wish to acknowledge and express the appreciation of funds received from the National Science Foundation - Advanced Technology Education (NSFATE DUE 0401990) program and the NASA REASoN project (REASoN-01180209) at San Diego State University.

\section{Reference}

Curran, J. (2005). Web-based Geospatial Information Services and Analytical Tools for Management of Real-time Surface Water Hydrology. Master's Thesis. Department of Geography, San Diego State University.

Garrett, J. J. (2002). The Elements of User Experiences: User-Centered Design for the Web. New York: American Institute of Graphic Arts.

Gould, M. D. (1989). Human Factors Research and its Value to GIS User Interface Design, Proceedings GIS/LIS '89, Orlando, Florida, pp. 542-550. 
ISO (1999). ISO 13407: Human Centered Design for Interactive Systems. International Organization for Standardisation, Geneva, Switzerland.

Mark, D. M., and Gould, M. D. (1991). Interacting with geographical information: A commentary, Photogrammetric Engineering and Remote Sensing, Vol. 57, No. 11, pp. 1427-1430.

Medyckyj-Scott, and Hearnshaw, H. M. edited. (1993). Human Factors in Geographical Information Systems, Belhaven Press, London.

Nielsen, J. (1994). Heuristic Evaluation. In Usability Inspection Methods, eds. J. Nielsen and R. Mack, New York: Wiley, pp. 25-62.

Nielsen, J. (1993). Usability Engineering. Academic Press. San Diego, California.

Nivala, A.-M, Sarjakoski, L. T. And T. Sarjakosko. (2005). User-Centered Design and Development of a Mobile Map Service. In the Proceedings of Scandinavian Research Conference on GIScience (ScanGIS), p. 109-123.

Nyerges, T., Mark D., Egenhofer M., and Laurini R. (eds.), (1995). Cognitive Aspects of Human-computer Interaction for Geographic Information Systems, Papers from the NATO Advanced Research Workshop, Mallorca, Spain, March 21-25, 1994. Dordrecht : Kluwer Academic Publishers, September, 1995.

Peng, Z.R., \& Tsou, M.H. (2003). Internet GIS: distributed geographic information services for the Internet and wireless networks. New York, John Wiley \& Sons, Inc.

Peterson, M. (1999). Chapter 3. Elements of Multimedia Cartography. In Cartwright W, Peterson M. P., and Gartner G. edited. Multimedia Cartography. Pp. 31-38.

Robinson, A. H. (1952). The Look of Maps. University of Wisconsin Press, Madison, Wisconsin.

Shneiderman, B. (1998). Designing the User Interface. Strategies for Effective Human-Computer Interaction. 3rd. edition. Addison-Wesley.

Tsou, M.H. (2003). Chapter 14: An Intelligent Software Agent Architecture for Distributed Cartographic Knowledge Bases and Internet Mapping Services. In Maps and the Internet, M. Peterson (ed), Elsevier Press, pp. 229-243.

Tsou, M.H. (2004). Integrating Web-based GIS and On-line Remote Sensing Facilities for Environmental Monitoring and Management. In special issue on the potential of Web-based GIS, the Journal of Geographical Systems. 6(2), pp. 155-174.

Tsou, M.H. and Buttenfield, B.P. (1997). A Direct Manipulation Interface for Geographical Information Processing. In: Kraak, M.J. and Melenaar, M. (eds.) Advances in GIS Research II. Taylor \& Francis, London, U.K., pp. 905-915 
